\title{
INDICADORES CLÍNICOS DE REFERÊNCIA AO DESENVOLVIMENTO INFANTIL E SUA RELAÇÃO COM FATORES OBSTÉTRICOS, PSICOSSOCIAIS E SOCIODEMOGRÁFICOS
}

Antônia Motta Roth Jobim van Hoogstraten

Doutoranda em Distúrbios da Comunicação Humana pela Universidade Federal de Santa Maria (RS), Brasil.

\section{Ana Paula Ramos de Souza}

Doutorado em Lingüística e Letras pela Pontifícia Universidade Católica do Rio Grande do Sul. Docente do quadro efetivo do departamento de Fonoaudiologia da Universidade Federal de Santa Maria e nos Programas de Pós-Graduação em Distúrbios da Comunicação Humana e de Psicologia da Universidade Federal de Santa Maria (UFSM), Brasil.

\section{Anaelena Bragança de Moraes}

Doutorado em Epidemiologia pela Universidade Federal do Rio Grande do Sul. Docente adjunto I da Universidade Federal de Santa Maria, Brasil.
RESUMO: Este estudo tem como objetivo relacionar os resultados obtidos por meio do roteiro Indicadores Clínicos de Referência ao Desenvolvimento Infantil (IRDI) com fatores obstétricos, psicossociais e sociodemográficos. Foram acompanhados 25 bebês nascidos pré-termo e 55 nascidos a termo entre os três e nove primeiros meses de vida, enfocando a presença ou ausência de risco psíquico. As variáveis que apresentaram relação com o desfecho presença de risco psíquico foram o bebê ser do sexo masculino, o tipo de aleitamento nos seis primeiros meses ser exclusivo ou acompanhado de fórmula infantil, a mãe não possuir um companheiro que lhe auxilie nos cuidados do bebê, a mãe ter idade entre 20 e 35 anos e o bebê não conseguir dormir sozinho em seu berço ou carrinho aos nove meses. Tais fatores apresentaram-se associados a alterações na relação mãe-bebê, repercutindo no resultado do IRDI, consequentemente, assinalando para possíveis impasses na constituição psíquica e/ou em outros aspectos do desenvolvimento infantil.

PALAVRAS-CHAVE: Desenvolvimento infantil; Psicanálise; Autismo; Relações mãe-filho; Prematuridade.

\section{REFERENCE CLINICAL INDEXES FOR CHILDREN'S DEVELOPMENT AND THEIR RELATIONSHIP WITH OBS- TETRIC, PSYCHOSOCIAL AND SOCIODEMOGRAPHIC FACTORS}

\begin{abstract}
Results from Reference Clinical Indexes for Children's Development (IRDI) and obstetric, psychosocial and sociodemographic factors are compared and contrasted. Twenty-five pre-term and 55 term children, aged 3-9 months old, were analyzed, focusing on the presence or absence of psychic risk. Variables with a relationship to psychic risk were male children, type of feeding during the first six months, exclusive or formulated, mother without any partner that helps in baby care, mother's age between 20 and 35 years old, and the child not sleeping alone in the cot or perambulator after nine months. The above factors were associated with alteration in mother-child relationship, affected IRDI and, consequently, indicating impairments for the psychic constitution and/or other aspects in child development.
\end{abstract}

KEY WORDS: Child Development; Psychoanalysis; Autism; Mother-child relations; Prematurity. 


\section{INTRODUÇÃO}

A possibilidade de identificar a existência de sofrimento psíquico precocemente que incide sobre a emergência de uma psicopatologia ou de algum atraso no desenvolvimento, vem sendo investigada por pesquisadores que partem da relação que se estabelece entre o bebê e aqueles que exercem as funções parentais para pensar a constituição psíquica. Com base no pressuposto de que a linguagem que compartilham é integrante da estruturação do funcionamento psíquico e a constituição do psiquismo é entendida como elemento organizador do desenvolvimento infantil em todas as suas vertentes (física, cognitiva, linguística e psicomotora), tais estudos têm servido de referência na busca de alternativas para a detecção e intervenção precoce ou a tempo, nos casos em que se evidenciam risco para perturbações da comunicação e da interação em bebês que podem rumar para uma estruturação de tipo autista ${ }^{1-7}$.

Os Indicadores Clínicos de Referência ao Desenvolvimento Infantil (IRDI) ${ }^{3,4}$ surgem, a partir da construção de um roteiro clínico que pode contribuir para a observação do modo como o trabalho do agente da função materna é tecido em torno de operações formadoras fundamentais do psiquismo do bebê, bem como o modo como o bebê responde a tais inscrições. Aqui, o agente da função materna ${ }^{9}$ é visto enquanto aquele que ampara o bebê em termos psíquicos e físicos, sendo capaz de se adaptar de forma sensível às suas necessidades iniciais, ofertando-lhe o olhar, o toque e a voz para, gradativamente, inscrevê-lo no campo da linguagem. Para tanto, é fundamental que a posição paterna ou de alteridade também esteja operando nos cuidados parentais. Ela também é objeto de análise dos indicadores, sobretudo entre oito e 18 meses $^{1}$.

$O$ roteiro IRDI resulta de pesquisa multicêntrica desenvolvida no período de 2004 a 2008, que teve como objetivo criar e validar indicadores clínicos aplicáveis nas consultas pediátricas de rotina, visando detectar, ainda na primeira infância, a incidência de risco psíquico e problemas de desenvolvimento infantil, sob a perspectiva da teoria psicanalítica. Dessa forma, tornar-se-ia possível o acompanhamento precoce dos casos em que foi evidenciada a presença de suspeita de problemas na estruturação psíquica ${ }^{3,4}$.
Para tal, foram definidas quatro operações formadoras, a partir da experiência clínica psicanalítica e que tem como resultado a instalação de um sujeito psíquico. Os quatro eixos ${ }^{3,4}$, observáveis a partir de sinais fenomênicos, são: suposição de um sujeito, alternância presença/ausência, estabelecimento da demanda e função paterna. Tais operações são formadoras de uma matriz fundamental que regula, organiza e determina as relações do sujeito com o mundo e consigo mesmo.

Dessa forma, na pesquisa IRDI, privilegiou-se, sem desconsiderar o âmbito da maturação, a articulação entre desenvolvimento e sujeito psíquico ${ }^{3}$, este último pensado enquanto instância psíquica inconsciente que é construída desde o início da vida da criança, a partir do campo social onde ela está imersa. Nessa perspectiva, a cultura e a linguagem são transmitidas à criança desde a mais tenra idade na relação com seus cuidadores - especialmente a mãe - e deverão lhe instrumentalizar com significações para que ela construa um lugar para si no mundo.

A análise estatística evidenciou que $o$ roteiro IRDI, com seus 31 indicadores, "possui uma capacidade maior de predizer problemas de desenvolvimento do que a capacidade de predizer risco psíquico" ${ }^{\text {. }}$. Tais evidências demonstraram maior amplitude do instrumento, quando considerada a intenção inicial da pesquisa que era, justamente, identificar sinais precoces de evolução posterior de patologias graves, como o autismo e a psicose. Mesmo assim, pôde-se verificar que alguns indicadores apresentaram maior predição de risco psíquico de um modo genérico ou sem especificação de patologia. Desses, quatro indicadores isoladamente e três grupos de indicadores, totalizando 18 indicadores, apresentaram sensibilidade para predizer risco à constituição do sujeito. A partir de então, foi desenvolvido um instrumento composto por um "conjunto de 18 indicadores cujas ausências foram validadas como capazes de detectar risco psíquico" ${ }^{4}$ de modo mais potente.

Cavalcanti ${ }^{10}$ salienta que uma das conclusões que a pesquisa IRDI quer evitar é de que seus indicadores sejam tomados como hipótese diagnóstica em tão tenra idade. Eles devem ser tomados como sinais positivos de desenvolvimento cuja ausência sinaliza a presença de sofrimento psíquico, que pode levar a um quadro de 
psicopatologia grave (risco psíquico) ou a obstáculos ao desenvolvimento (risco ao desenvolvimento). Não devem ser tomados como uma profecia negativa, mas como sinais de alerta.

Sob tal perspectiva, quando se trata de diagnóstico de estrutura na infância, de modo geral, há espaço para reversões e modificações. Por esse motivo, é fundamental cautela para não ser taxativo, congelando o sujeito em uma determinada posição estrutural ${ }^{8}$. O termo risco psíquico ${ }^{3,4}$ localiza, dessa forma, uma possibilidade de evolução em direção a psicopatologias graves da infância, tais como as psicoses infantis, as psicopatologias que apresentam traços autistas e o próprio autismo. E, ao mesmo tempo, coloca uma possibilidade de reversão do quadro quando tais sinais são identificados a tempo de uma intervenção nos primeiros anos de vida.

Os indicadores de referência, quando presentes, evidenciam que a constituição do psiquismo segue um caminho rumo à saúde mental. Em sua ausência, devem ser tomados como uma oportunidade de sustentar outro caminho ao bebê e seus familiares para que o risco seja ultrapassado antes que sintomas se cristalizem e dificultem, não apenas o desenvolvimento do bebê no presente, como também em fases evolutivas posteriores. Tais consequências podem apresentar efeitos nos processos de aquisição da linguagem, dos processos cognitivos que embasam a aprendizagem escolar e da adaptação no cotidiano, bem como de adaptação social ${ }^{3,4}$.

Kupfer et al. ${ }^{4}$ consideram o desenvolvimento humano como produto de uma dupla incidência, tomando os processos maturativos de ordem neurológica e genética de um lado e, de outro, os processos de constituição do sujeito psíquico. Nesse contexto, diferenciam o risco ao desenvolvimento do risco psíquico. Enquanto o primeiro seria fruto de dificuldades subjetivas que afetam ou incidem no desenvolvimento da criança, mas que não questionam a instalação de um sujeito psíquico, tais como os casos de hiperatividade, de sintomas psicomotores como a agitação motora, a enurese, encoprese, entre outros. O risco psíquico estaria relacionado a entraves na constituição subjetiva que gerariam problemas na estruturação rumo à emergência de uma psicopatologia gra$\mathrm{ve}^{5}$, tais como autismos, psicoses e, de um modo geral, os denominados "distúrbios globais do desenvolvimento".
$O$ roteiro IRDI vem sendo utilizado em pesquisas, tais como a de Crestani et al. ${ }^{11}$, com o objetivo de investigar os riscos ao desenvolvimento em relação às funções parentais, impasses no processo de aquisição da linguagem, bem como variáveis sociodemográficas, obstétricas e psicossociais. Essas pesquisas utilizaram o IRDI em conjunto com avaliações de linguagem a partir do campo fonoaudiológico e avaliações dos estados emocionais maternos e exercício das funções parentais a partir do campo psicológico. Esses estudos evidenciaram relações estatisticamente significativas entre a constituição psíquica e a emergência de aspectos estruturais e instrumentais do desenvolvimento do bebê.

Partindo da literatura investigada, este artigo tem como objetivo analisar as associações entre risco psíquico/desenvolvimento e fatores obstétricos, psicossociais e sociodemográficos.

\section{MÉTODO}

A amostra total para o estudo foi de 80 bebês e suas mães, sendo 55 bebês nascidos a termo e 25 bebês prematuros cujas avaliações consideraram a idade corrigida. Essa amostra foi definida a partir dos bebês que completaram todas as avaliações previstas no roteiro IRDI no período de zero a nove meses, considerando um grupo maior de 140 bebês e seus familiares convidados para a pesquisa.

Em relação à idade corrigida ${ }^{12}$, salienta-se que a mesma foi calculada a partir da subtração entre a idade cronológica do bebê, em semanas, menos 40 semanas. Essa diferença foi somada à idade cronológica para se descobrir a data corrigida do nascimento do bebê.

Foram convidadas a participar deste estudo todas as mães cujos bebês apresentavam idade inferior a um mês, tanto os bebês nascidos a termo quanto os prematuros, no período entre agosto de 2014 e maio de 2015 , que frequentavam ao menos um dois locais de puericultura onde a pesquisa foi realizada. Eles foram convidados no setor do teste do pezinho na Unidade Básica de Saúde - UBS próxima ao hospital universitário, escolhida por ter uma quantidade de 150 nascimentos anuais, e no setor de acompanhamento de prematuros extremos do 
hospital universitário de uma cidade de porte médio do Rio Grande do Sul. No primeiro setor foram convidadas a participar as mães dos bebês a termo e prematuros moderados e tardios. No hospital, foram convidadas as mães dos bebês prematuros extremos que permaneceram ou não em internação na Unidade Terapia Intensiva neonatal após o nascimento.

Foram excluídos todos os bebês que apresentaram qualquer espécie de síndrome genética (síndrome de Down, X-frágil etc.), lesões neurológicas como encefalopatia crônica não progressiva, ou déficits sensoriais como surdez ou déficit visual. Esse critério de exclusão foi garantido nos bebês prematuros a partir das avaliações que o seguimento de prematuros do hospital universitário realiza quando estes foram encaminhados e no caso dos bebês a termo, a partir das avaliações que os pediatras fizeram na UBS. Diante de qualquer suspeita de déficits sensoriais ou outras limitações orgânicas, os bebês foram encaminhados para exames médicos e seus dados retirados da amostra.

\section{ASPECTOS ÉTICOS}

Essa pesquisa, conforme normas regulamentadas pela resolução 466/2012 (BRASIL resolução no 466, de 12 de dezembro de 2012), passou por aprovação do Comitê de Ética e Pesquisa em Saúde (CEP) da UFSM e por autorização da secretaria municipal de saúde, inserida no projeto maior intitulado "Análise Comparativa do Desenvolvimento de Bebês Prematuros e a Termo e sua Relação com Risco Psíquico: da detecção à intervenção", autorizado em maio de 2014 no CEP - UFSM sob número do parecer 652.722 .

A pesquisa não ofereceu riscos físicos ou morais para os participantes, uma vez que os exames realizados pela equipe são procedimentos simples e não invasivos. O único desconforto foi a necessidade de que as díades comparecessem ao local de avaliação para que fossem feitas as filmagens e as avaliações.

Nos casos em que foi identificado risco para perturbações da comunicação e da interação, as crianças foram encaminhadas para intervenção, sobretudo quando se identificou risco grave. Nem todos os bebês seguiram para tratamento, a partir da indicação da equipe, pois houve necessidade de estabelecer a demanda para tanto. $O$ fato de a equipe identificar uma demanda por intervenção não significa que a família assim percebesse. Por isso, priorizaram-se casos mais graves nos quais foi insistido aos pais algum tipo de intervenção, entre seis e nove meses, visto que se percebeu que aos seis meses vários bebês ficaram bem. A permanência de sinais de risco nesta faixa etária é o que determinou o encaminhamento para intervenção.

\section{PROCEDIMENTOS E INSTRUMENTOS}

No primeiro contato com as díades foram expostas e atendidas as demandas éticas da pesquisa. Foi entregue a todas as mães que aceitaram participar da pesquisa um Termo de Consentimento Livre e Esclarecido (TCLE) constando os objetivos da pesquisa, os riscos envolvidos, a participação voluntária, o sigilo quanto a sua identidade e de seu bebê, bem como o seu direito de desistir do processo em qualquer momento do estudo. Ainda nesse primeiro encontro, as mães foram convidadas a responder uma entrevista inicial semiestruturada, com a qual foram coletados dados referentes aos aspectos sociodemográficos, psicossociais e obstétricos analisados neste estudo.

Depois do primeiro contato, foram previstos outros três encontros em que as díades foram filmadas e avaliadas, a partir da interação, quanto à presença ou ausência de indicadores do roteiro IRDI. Tal avaliação foi realizada antes do início de cada uma das três filmagens sendo os resultados, quando necessários, confirmados pela pesquisadora e sua orientadora por meio da observação das imagens captadas.

Nas filmagens, a interação mãe-bebê foi gravada ao longo de 09 minutos. Nesse intervalo de tempo, houve uma padronização das posturas dos bebês, variando de acordo com as habilidades motoras previstas para sua idade e das suas habilidades pessoais. Foram utilizados brinquedos e posturas adequados para a faixa etária. As mães eram orientadas a cantar, conversar e brincar com os filhos do modo que desejassem. Foram utilizadas duas câmeras, sendo uma delas colocada a 01 metro de distância da díade, em visão lateral, para captar interação face a face entre mãe e bebê e a outra, a 02 metros, em visão 
frontal, para captar as expressões faciais da mãe em espelho colocado atrás do bebê conforto (nas idades de $04 \mathrm{e}$ 06 meses). Na idade de oito meses, o espelho permitia visualizar expressões da mãe e do bebê já que ele poderia posicionar-se livremente. Essas filmagens permitiram a conferência dos resultados do roteiro IRDI observados na entrevista antes do início da filmagem.

Os resultados no roteiro IRDI foram obtidos a partir da avaliação da interação mãe-bebê em cada uma das fases e foi considerada a presença de alguma alteração no roteiro quando dois ou mais indicadores estiveram ausentes. A avaliação dos bebês, a partir da aplicação do roteiro IRDI, foi realizada em três momentos ao longo dos nove meses: Fase I (avaliação feita entre 3-4 meses), Fase II (avaliação feita entre 6-7 meses e 29 dias) e Fase III (avaliação feita entre 8-9 meses e 29 dias).

\section{INSTRUMENTOS}

\section{Entrevistas Semiestruturadas}

A entrevista semiestruturada foi construída a partir do roteiro utilizado em Crestani ${ }^{13}$, adaptada para esta pesquisa, a partir da discussão do grupo e dos inúmeros objetivos do projeto e pesquisa. O roteiro abordou dados psicossociais (planejamento da gestação, apoio da família, dentre outros), obstétricos (pré-natal, tipo de parto, intercorrências, dentre outros) e sociodemográficos (sexo do bebê, idade materna, escolaridade, estado civil e profissão materna e paterna, dentre outros), por meio de perguntas simples apresentadas à mãe e/ou quem fizesse a função materna, em caso de ausência desta. As mães biológicas exerciam a função materna para os 80 bebês desta pesquisa.

A entrevista foi realizada no primeiro encontro quando as mães assinaram o TCLE e, nos encontros seguintes foi realizada uma atualização da entrevista (entrevista continuada), buscando compreender as modificações na rotina e hábitos dos bebês. As entrevistas foram realizadas nas mesmas ocasiões em que foram verificados os indicadores do roteiro IRDI.

\section{Protocolos de Avaliação Padronizados}

Indicadores clínicos de referência ao desenvolvimento infantil

Foram utilizados os indicadores do IRDI (versão reduzida) referentes às Fases I, II e III. A seguir, o Quadro 1 com os indicadores das três primeiras fases utilizados na pesquisa.

Quadro 1. Indicadores roteiro IRDI versão reduzida

\begin{tabular}{|l|c|}
\hline FASE I - O A 4 MESES INCOMPLETOS & EIXOS \\
\hline $\begin{array}{l}\text { 1. Quando a criança chora ou grita, a mãe sabe o que } \\
\text { ela quer. }\end{array}$ & SS/ED \\
\hline $\begin{array}{l}\text { 2. A mãe fala com a criança num estilo particularmen- } \\
\text { te dirigido a ela (manhês). }\end{array}$ & SS \\
\hline 3. A criança reage ao manhês. & ED \\
\hline 4. A mãe propõe algo à criança e aguarda sua reação. & PA \\
\hline 5. Há trocas de olhares entre a criança e a mãe. & SS/PA \\
\hline FASE II - 4 A 8 MESES INCOMPLETOS & ED \\
\hline $\begin{array}{l}\text { 6. A criança utiliza sinais diferentes para expressar } \\
\text { suas diferentes necessidades. }\end{array}$ & ED \\
\hline $\begin{array}{l}\text { 7. A criança reage (sorri, vocaliza) quando a mãe ou } \\
\text { outra pessoa está se dirigindo a ela. }\end{array}$ & ED/PA \\
\hline 8. A criança procura ativamente o olhar da mãe. & SS/PA \\
\hline FASE III - 8 A 12 MESES INCOMPLETOS & FP \\
\hline $\begin{array}{l}\text { 9. A mãe percebe que alguns pedidos da criança po- } \\
\text { dem ser uma forma de chamar a sua atenção. }\end{array}$ & ED/SS \\
\hline $\begin{array}{l}\text { 10. Durante os cuidados corporais, a criança busca } \\
\text { ativamente jogos e brincadeiras amorosas com a mãe. }\end{array}$ & ED \\
\hline $\begin{array}{l}\text { 11. Mãe e criança compartilham uma linguagem par- } \\
\text { ticular. }\end{array}$ & ED \\
\hline \begin{tabular}{l} 
12. A criança estranha pessoas desconhecidas para ela. \\
13. A criança faz gracinhas. \\
\hline $\begin{array}{l}\text { 14. A criança aceita alimentação semissólida, sólida e } \\
\text { variada. }\end{array}$
\end{tabular} \\
\hline
\end{tabular}

ED- Estabelecimento da demanda, FP- Função paterna, PA- alternância entre presença e ausência, SS- Suposição de sujeito

Fonte: Kupfer et $a^{3}$.

\section{ANÁLISE GERAL DOS DADOS}

Para a análise das variáveis avaliadas, após a coleta dos dados por meio do roteiro IRDI, entrevista e filma- 
gem das díades, os dados foram reunidos e construiu-se um banco de dados transferido para planilhas do Excel e atualizados de acordo com cada uma das três fases avaliadas dos bebês.

Para a análise estatística, utilizaram-se os aplicativos computacionais Statistica 9.1 e PASW///. Em relação aos testes aplicados, efetuou-se um Modelo de Regressão Logística Múltipla dos resultados obtidos com os IRDI. A regressão logística considerou um nível de significância de $10 \%$ com o objetivo de verificar o desfecho "presença de risco" que se associava a fatores sociodemográficos, obstétricos e psicossociais coletados nas entrevistas.

Em relação ao nível de significância, foi considerado o valor de $10 \%$, tendo em vista o tamanho da amostra disponível para a construção do modelo de regressão logística múltipla. Por esse motivo, houve a necessidade de aumentar em $5 \%$ a probabilidade de comentar o erro do tipo 1 (alfa). Se fosse considerado o nível de significancia de 5\%, alguns dos fatores importantes que incidem sobre o desfecho "presença de risco" estariam fora do modelo, tais como o sexo do bebê e a presença de um cônjuge que auxilia a mãe nos cuidados do bebê.

Para a regressão logística múltipla, inicialmente, todas as variáveis coletadas nas entrevistas foram categorizadas, uma a uma, em duas faixas. Para a seleção das variáveis candidatas ao modelo de regressão, foi utilizado o nível de significância inicial de $25 \%$, a partir de um modelo de regressão simples. Todas as variáveis consideradas significativas foram testadas conjuntamente no modelo de regressão logística múltipla em relação ao desfecho "presença de risco no roteiro IRDI". Em cada nova rodagem da estatística, excluíram-se aquelas variáveis que, conjuntamente, apresentaram um p valor superior a 10\%, de acordo com o método "Enter". Salienta-se que a verificação da significância das variáveis foi realizada pelo teste de Wald, tanto para as Razões de Risco (OR) bruto quanto para o OR ajustado. Ao término, foram consideradas todas as variáveis que, em conjunto, apresentaram um p valor igual ou menor a $10 \%$ para o desfecho "Presença de risco no IRDI", em cada uma das três fases avaliadas.

Ressalta-se ainda que, diferentemente das demais variáveis do modelo, a variável "idade materna acima de 35 anos" foi identificada enquanto um fator de proteção para o desenvolvimento do bebê na amostra estudada, tendo em vista que seu resultado de OR ajustado foi inferior a um, isto é, OR ajustado $=0,204$, quando avaliada dentro do modelo proposto.

\section{RESULTADOS}

Os resultados obtidos a partir da aplicação do roteiro IRDI, nas faixas etárias avaliadas, pode ser observado nas tabelas de frequência 1 .

Tabela 1. Frequência dos bebês a termo e prematuros com indicadores ausentes nas fases I, II e III

\begin{tabular}{|c|c|c|c|c|c|c|c|}
\hline & \multirow{2}{*}{$\begin{array}{l}\text { Número e } \\
\text { percentual } \\
\text { bebês em } \\
\text { risco }\end{array}$} & \multicolumn{6}{|c|}{$\begin{array}{l}\text { Número de indicadores au- } \\
\text { sentes }\end{array}$} \\
\hline & & 2 & 3 & 4 & 5 & 6 & 7 \\
\hline \multicolumn{8}{|l|}{ FASE I } \\
\hline $\begin{array}{l}\text { Prematuros } \\
(\mathrm{n}=25)\end{array}$ & $10(40 \%)$ & 10 & & & & & \\
\hline A termo $(\mathrm{n}=55)$ & 15 (27,27\%) & 8 & 5 & 2 & & & \\
\hline Total $(n=80)$ & $25(31,25 \%)$ & 18 & 5 & 2 & & & \\
\hline \multicolumn{8}{|l|}{ FASE II } \\
\hline $\begin{array}{l}\text { Prematuros } \\
(\mathrm{n}=25)\end{array}$ & $11(44 \%)$ & 4 & 7 & 0 & 0 & 0 & 0 \\
\hline A termo $(\mathrm{n}=55)$ & $13(23,64 \%)$ & 2 & 3 & 4 & 3 & 1 & 0 \\
\hline Total $(n=80)$ & $24(30 \%)$ & 18 & 10 & 4 & 3 & 1 & 0 \\
\hline \multicolumn{8}{|l|}{ FASE III } \\
\hline $\begin{array}{l}\text { Prematuros } \\
(\mathrm{n}=25)\end{array}$ & $6(24 \%)$ & 0 & 3 & 3 & 0 & 0 & 0 \\
\hline A termo $(\mathrm{n}=55)$ & $11(20 \%)$ & 0 & 0 & 2 & 4 & 1 & 4 \\
\hline Total $(n=80)$ & $17(21,25 \%)$ & 0 & 3 & 5 & 4 & 1 & 4 \\
\hline
\end{tabular}

Fonte: Autores.

Na Tabela 2 são apresentados, respectivamente, as frequências, os percentuais, os OR ajustados e seus respectivos intervalos de confiança, para cada uma das fases avaliadas, considerando as variáveis sociodemográficas, psicossociais e obstétricas que foram significativas no modelo de regressão logística múltipla. 
Tabela 2. Variáveis sociodemográficas, psicossociais e obstétricas selecionadas no modelo de regressão logística múltipla nas fases II e III do roteiro IRDI

\begin{tabular}{|c|c|c|c|c|c|}
\hline \multirow[b]{2}{*}{ Fase II } & \multicolumn{3}{|c|}{ IRDI } & \multirow[b]{2}{*}{ IC $90 \%$} & \multirow[b]{2}{*}{$\mathrm{p}$ - valor } \\
\hline & $\begin{array}{l}\text { Sem ris- } \\
\text { co (\%) }\end{array}$ & $\begin{array}{c}\text { Com } \\
\text { risco }(\%)\end{array}$ & $\begin{array}{c}\text { OR } \\
\text { Ajus }\end{array}$ & & \\
\hline \multicolumn{6}{|c|}{ Tipo de aleitamento } \\
\hline $\begin{array}{l}\text { Materno exclu- } \\
\text { sivo }\end{array}$ & $\begin{array}{c}34 \\
(80,95 \%)\end{array}$ & $\begin{array}{c}8 \\
(19,05 \%)\end{array}$ & 1 & & \\
\hline $\begin{array}{l}\text { Misto e/ou arti- } \\
\text { ficial }\end{array}$ & $\begin{array}{c}22 \\
(57,89 \%)\end{array}$ & $\begin{array}{c}16 \\
(42,11 \%)\end{array}$ & 3,229 & $\begin{array}{c}1,349- \\
7,728\end{array}$ & 0,027 \\
\hline \multicolumn{6}{|c|}{ Como criança dorme } \\
\hline $\begin{array}{l}\text { Consegue dor- } \\
\text { mir sozinha no } \\
\text { berço ou carri- } \\
\text { nho }\end{array}$ & $\begin{array}{c}18 \\
(90,00 \%)\end{array}$ & $\begin{array}{c}2 \\
(10,00 \%)\end{array}$ & 1 & & \\
\hline $\begin{array}{l}\text { Apenas com os } \\
\text { pais na cama }\end{array}$ & $\begin{array}{c}38 \\
(63,33 \%)\end{array}$ & $\begin{array}{c}22 \\
(36,67 \%)\end{array}$ & 5,481 & $\begin{array}{l}1,450- \\
20,711\end{array}$ & 0,035 \\
\hline
\end{tabular}

Fase III

Mãe com côn-

juge que auxi-

lia nos cuida-

dos do bebê

\begin{tabular}{|c|c|c|c|c|c|}
\hline Sim & $\begin{array}{c}55 \\
(80,89 \%)\end{array}$ & $\begin{array}{c}13 \\
(19,11 \%)\end{array}$ & 1 & & \\
\hline Não & $\begin{array}{c}8 \\
(66,67 \%)\end{array}$ & $\begin{array}{c}4 \\
(33,33 \%)\end{array}$ & 4,322 & $\begin{array}{l}1,254- \\
14,891\end{array}$ & 0,052 \\
\hline \multicolumn{6}{|c|}{ Sexo do bebê } \\
\hline Feminino & $\begin{array}{c}35 \\
(87,05 \%)\end{array}$ & $\begin{array}{c}5 \\
(12,05 \%)\end{array}$ & 1 & & \\
\hline Masculino & $\begin{array}{c}28 \\
(70,00 \%)\end{array}$ & $\begin{array}{c}12 \\
(30,00 \%)\end{array}$ & 2,855 & $\begin{array}{c}1,035- \\
7,873\end{array}$ & 0,089 \\
\hline
\end{tabular}

Idade mater-

na (anos)

\begin{tabular}{lccccc}
\hline Entre 20 e 35 & 44 & 15 & 1 & & \\
& $(74,58 \%)$ & $(25,42 \%)$ & & & \\
Acima de 35 & 19 & 2 & 0,204 & $0,047-$ & 0,076 \\
& $(90,48 \%)$ & $(9,52 \%)$ & & 0,892 &
\end{tabular}

IRDI- indicadores clínicos de referência ao desenvolvimento OR $\mathrm{Aj}=$ odds ratio ajustado;

$\mathrm{C}=$ Intervalo de confiança.

Fonte: Dados da pesquisa.

$\mathrm{Na}$ Tabela 2, verificam-se os principais fatores sociodemográficos, psicossociais e obstétricos que influenciaram para o desfecho presença de risco para o roteiro IRDI nas três fases avaliadas.

$\mathrm{Na}$ fase entre os quatro meses e um dia e sete meses e 29 dias, o modelo de regressão logística mostrou como fatores de risco significativos: o tipo de aleitamento e como e com quem a criança dorme. Bebês que foram alimentados com leite materno exclusivo até o sexto mês apresentaram duas vezes menos chance de apresentar dois ou mais indicadores ausentes nas fases I e II quando comparados àqueles alimentados com leite artificial.

Outro fator que apresentou risco significativo foi com quem a criança dorme. Crianças que já estavam conseguindo dormir sozinhas em seu berço apresentaram quatro vezes menos chance de apresentar dois ou mais indicadores ausentes nas fases I e II do roteiro IRDI do que aquelas que dormiam na cama com os pais ou outros cuidadores.

Por fim, o modelo de regressão logística mostrou como fatores de risco significativos para indicadores da fase III, avaliados na faixa etária entre oito meses e um dia e nove meses e 29 dias, a idade materna, se a mãe possuía um cônjuge e o sexo do bebê.

A idade materna acima de 35 anos foi um fator de proteção para o desenvolvimento do bebê na amostra estudada, como já mencionado anteriormente. Pôde-se verificar que as mães que apresentaram idade acima de 35 anos reduziram em $79,6 \%$ a probabilidade de ter um bebê com dois ou mais indicadores ausentes do que as mães de idade entre 20 e 35 anos. Ressalta-se que dentre as dez mães com idade inferior a 20, sendo seis com 19 anos, duas com 18 anos e duas com 16 anos, nenhuma apresentou bebês com risco ou sofrimento psíquico na fase III.

Na terceira fase, foram ainda fatores de risco significativos o fato da mãe não possuir um cônjuge que lhe auxiliasse nos cuidados do bebê. Mães nessas condições apresentaram 4,6 vezes a chance de seus filhos apresentarem sofrimento ou risco em relação àquelas que tinham um cônjuge. Portanto, a presença do cônjuge que apoiasse nos cuidados parentais demonstrou ser um fator de proteção, representando um facilitador para a constituição psíquica e para o desenvolvimento infantil na fase estudada.

Ainda na fase III, o sexo do bebê também apareceu como um fator de risco significativo. Nesse sentido, bebês do sexo masculino apresentaram 2,8 vezes a chance de terem dois ou mais indicadores ausentes nas três primeiras fases quando comparados aos bebês do sexo feminino. 


\section{DISCUSSÃO}

Na regressão logística múltipla é interessante observar a possibilidade de se utilizar o roteiro IRDI para avaliar o desenvolvimento infantil e, em especial, a constituição psíquica ${ }^{14,15}$, bem como a influência de diversos fatores para a existência de risco psíquico, inclusive alguns relacionados ao momento do nascimento do bebê, bem como fatores maternos, como a idade, a presença de atividade profissional e de um cônjuge. Tais resultados demonstram a complexidade de se investigar a experiência da relação do bebê com aqueles que exercem as funções parentais no que se refere ao seu potencial comunicativo e constituinte. Permitem, também, lançar a hipótese de que o desenvolvimento biológico, psíquico e cognitivo de um bebê encontra-se intimamente entrelaçado com os fatores socioeconômicos, demográficos, psicossociais que marcam a história familiar na qual está inserido.

Em relação aos aspectos biológicos, percebe-se que, apesar de a prematuridade não ter sido uma variável estatisticamente significativa nos resultados da regressão logística, tal como encontrado na literatura sobre desenvolvimento infantil e prematuridade ${ }^{16,17,18}$, percebe-se que na Fase I, 40\% dos bebês prematuros apresentaram ao menos dois indicadores ausentes, ao passo que os bebês a termo representaram $27,27 \%$ dos casos com dois ou mais indicadores ausentes. É importante lembrar que, apesar de ter sido considerado risco na Fase I dois ou mais IRDI ausentes, a ausência de qualquer um dos indicadores da Fase I permite sinalizar para atenção a possíveis impasses na qualidade do laço mãe-bebê. Cabe lembrar que esses indicadores analisam a possibilidade do exercício da função materna, por meio da suposição do que o bebê deseja quando chora, da qualidade do manhês utilizado para se comunicar com ele, da possibilidade da mãe ou quem faça sua função lançar uma demanda e aguardar a resposta do bebê e da ocorrência de trocas de olhares entre a díade. Por esse motivo, a ausência de qualquer um dos cinco primeiros indicadores marca que algo da estruturação do sujeito pode não estar indo bem e, por isso, tornam-se fatores de risco à estruturação psíquica.

Schjolberg et al. ${ }^{16}$ encontraram resultados que sugerem que o gênero masculino, baixo peso ao nascer e idade gestacional ou múltiplos nascimentos também apresentaram uma associação estatisticamente significativa em relação a baixos escores de linguagem. Quanto aos aspectos instrumentais como a psicomotricidade, estudos demonstram que há diferenças entre bebês prematuros e a termo. Reuner et al. ${ }^{17}$ verificaram a existência de relação entre atraso motor, idade gestacional inferior e peso ao nascer inferior a 1.500 . O sexo masculino também foi associado a posterior emergência de autismo no estudo de 554 bebês por Stephen et al. ${ }^{18}$. É visível nesta pesquisa a predominância de bebês do sexo masculino com risco psíquico tanto na análise quantitativa descritiva dos resultados dos casos.

Analisando, em específico, a questão do sexo do bebê, os resultados sugerem que bebês do sexo masculino apresentaram uma vez mais chance de ter ao menos dois indicadores ausentes nas três primeiras fases do roteiro IRDI. Essas evidências vão ao encontro dos primeiros resultados preliminares da pesquisa PREAUT em que, dos 24 bebês que apresentaram risco em um dos exames, houve prevalência do sexo masculino $(n=16)$ em relação ao feminino $(n=8)^{2}$.

Salienta-se, ainda, no que se refere às dificuldades encontradas na constituição psíquica dos bebês prematuros, os impasses encontrados na formação do vínculo entre o bebê e aqueles que exercem as funções parentais quando se é necessário um período de internação na UTI neonatal. Nesses casos, o nascimento do bebê configura-se em uma situação de risco para a família e, especialmente para a mãe, pois o período de internação pode interferir negativamente no estabelecimento do vínculo mãe-bebê e na possibilidade do exercício da função materna. Tais dificuldades são acentuadas diante da realidade que se apresenta em forma de um bebê na incubadora que, em nada se assemelha ao bebê fantasiado e diante da intensa angústia e culpa que acompanha os pais em relação ao futuro do bebê $\hat{e}^{19,20}$.

Essas dificuldades enfrentadas pelos pais de bebês prematuros e, em especial às mães, nos meses iniciais ao nascimento podem estar associadas aos resultados encontrados na primeira fase, em que $40 \%$ dos bebês apresentaram ao menos dois indicadores ausentes. Acredita-se que, por essa família ter atravessado, na maioria das vezes, um período de internação que pôde chegar até 60 
dias, o retorno para casa e as dificuldades para exercer as funções parentais pode ter repercutido nos resultados da primeira fase de avaliação (até 4 meses). A redução de risco na fase II e, sobretudo na fase III, indica que houve a reorganização familiar positiva a partir da alta hospitalar e convívio domiciliar. Nesse contexto, a questão que fica para estudos futuros é se, ao se introduzir um cuidado mais humanizado na UTI neonatal, com maior suporte psicológico e condições de exercício das funções parentais já no ambiente hospitalar, isso não repercutiria no estabelecimento do laço entre a mãe (ou substituta) e seu bebê, supondo aí um caminho para diminuir os sinais de risco à estruturação psíquica do bebê no primeiro trimestre de vida, em casos de prematuridade.

Sob tal perspectiva, salienta-se o estudo de Pretto-Carlesso et al. ${ }^{21}$ que evidenciou associação positiva entre a presença de risco ao desenvolvimento infantil, avaliados a partir do roteiro IRDI da Fase I e presença de sofrimento psíquico materno, sobretudo as mães com depressão que apresentaram dificuldades no estabelecimento de demanda de seus bebês.

Dentre os aspectos investigados na análise de associação entre as variáveis sociodemográficas e psicossociais com os resultados no roteiro IRDI fatores como a mãe ser solteira, separada ou não possuir um companheiro que lhe auxiliasse nos cuidados do bebê, não apresentar uma atividade profissional (seja ela estudar e/ ou trabalhar), ter idade entre 20 e 35 anos, utilizar aleitamento misto ou artificial nos primeiros seis meses, bem como o fato de o bebê ainda não ser capaz de dormir sozinho na faixa etária dos seis meses, foram fatores associados às dificudades na relação mãe-bebê, assinalando possíveis impasses na constituição psíquica ou do desenvolvimento do bebê.

Com relação à presença de cônjuge que auxilia nos cuidados do bebê, verificou-se que essa variável foi significativa na regressão logística com o resultado do roteiro IRDI fase III. Na fase III essa chance foi elevada em 4,6 vezes quando comparados aos bebês de mães que possuem um cônjuge participativo. Esse resultado reforça a importância da presença de um cônjuge desde o nascimento enquanto agente da função paterna, promovendo sustentação à mãe para que ela possa exercer sua função e atuando como terceiro na relação mãe-bebê que produz a separação necessária à constituição psíquica do bebê. Nesses termos, percebe-se, portanto, que a presença de um cônjuge ativo nos cuidados parece ser fator de proteção fundamental à constituição psíquica do bebê, conforme assinalam os estudos sobre constituição psíquica, sobretudo aqueles realizados com o roteiro $\operatorname{IRDI}^{3,4,11,13,20,21,24}$.

Crestani ${ }^{13}$ também verificou que o estado civil materno é um fator que incide sobre a presença de risco ao desenvolvimento do filho, a partir da análise do roteiro IRDI. A autora verificou que mães que possuem cônjuge apresentam duas vezes menos chance de ter um bebê com indicadores ausentes do que aquelas que não possuem cônjuge. Na mesma direção, estudos do campo psicológico demonstraram que a ausência de cônjuge representaram fator propulsor para que sintomas ansiosos e depressivos das puérperas se manifestassem, trazendo consequências negativas ao bebêt ${ }^{22}$.

Além do estado civil, ressalta-se a faixa etária materna. A idade materna acima de 35 anos foi um fator de proteção para o desenvolvimento do bebê. Verificou-se que as mães que apresentaram idade acima de 35 anos reduzem cerca de 79,6\% a probabilidade de ter um bebê com risco psíquico, a partir de indicadores ausentes no roteiro IRDI alterados na fase III em relação às mães de idade entre 20 e 35 anos. Esse resultado também foi encontrado no estudo de Crestani ${ }^{13}$, que encontrou que as mães com idade na faixa etária entre 20 e 34 anos apresentam nove vezes mais chance de ter um bebê com risco ao desenvolvimento infantil na Fase III dos IRDI, em relação às com menos de 20 anos ou acima de 35 anos. Acerca desse resultado é preciso ressaltar que era uma amostra de mães e bebês, constatada no mesmo hospital universitário e com perfil sociodemográfico similar.

Uma das hipóteses de Crestani ${ }^{13}$ para tal desfecho foi o fato de as mães estarem em plena idade produtiva e a grande maioria ser do lar sem perspectivas profissionais antes ou após o nascimento do bebê. Isso talvez tenha incidido sobre as condições de perspectiva social desse grupo e sobre os níveis de satisfação com o próprio desenvolvimento pessoal-profissional dessas mães. Essa é uma hipótese que se reforça neste estudo considerando a similaridade social das amostras, entretanto, tal aspecto carece de mais investigação sociológica na realidade de 
Santa Maria, cidade onde a pesquisa foi realizada.

Em relação ao aleitamento materno, a pesquisa de Cardoso $^{23}$ com uma amostra de 173 mães com o objetivo de investigar o que leva uma mãe a amamentar ou não e a continuar a amamentar ou desistir de fazê-lo, verificou-se que as mães que amamentam desejaram a gravidez, receberam informações sobre o aleitamento e desfrutaram de um contato imediato e alojamento conjunto com o recém-nascido. As mães que não amamentaram consideraram que o aleitamento dificultava sua rotina. Esses resultados podem ser relacionados aos resultados desta pesquisa que encontrou que bebês que receberam aleitamento materno exclusivo até o sexto mês apresentaram duas vezes menos chance de apresentar dois ou mais indicadores ausentes no roteiro IRDI nas duas primeiras fases em comparação àqueles alimentados com leite artificial. Percebe-se, desse modo, que o ato de amamentar é de fundamental importância no estabelecimento do vínculo entre a díade, envolvendo o olhar, o toque e a voz.

Ainda nesse contexto, ressalta-se a importância de lembrar dos estados emocionais maternos, pois podem repercutir diretamente na disponibilidade da mãe em se conectar com seu bebê e desejar amamentá-lo. Por isso, nos casos em que a mãe apresenta sintomas de sofrimento psíquico e/ou ansiedade, pode haver dificuldades no ato de amamentar e tomá-lo como ato prazeroso. Tal fator pode estar relacionado à dificuldade em alimentar o bebê, bem como dificuldade no aleitamento materno exclusivo, favorecendo práticas de aleitamento misto, tal como observado em Beltrami et al. ${ }^{24}$ e Crestani et al. ${ }^{11}$.

Outro fator que apresentou risco significativo evidenciado na Fase II do IRDI foi como e com quem a criança dorme. Bebês que já conseguiam, na faixa etária dos seis meses, dormir sozinhos em seu berço, mesmo acordando ao longo da noite e demandando a atenção da mãe, apresentaram quatro vezes menos chance de apresentar dois ou mais indicadores ausentes nas duas primeiras fases do roteiro IRDI, quando comparados àqueles que dormiam na cama com os pais ou outros cuidadores. Acredita-se que, apesar de não ter sido descrito na literatura pesquisada, este também é um fator que pode evidenciar impasses no exercício de separação entre mãe e bebê, refletindo uma dificuldade de operação da função paterna. Percebeu-se nesses casos que a pre- sença de risco se relacionava a indicadores que expressam o exercício da função paterna, bem como a dinâmica presença-ausência, eixos teóricos relevantes para pensar os processos de alienação-separação.

Os resultados estatísticos apresentados, apesar de não ilustrarem a singularidade de cada caso, fundamental para se compreender o contexto em que cada indicador é avaliado, permite que haja uma visão ampla de tendências que podem incidir sobre a constituição psíquica do bebê e seu desenvolvimento. A partir de então, pode-se discutir a respeito de algumas das condições sociodemográficas e obstétricas necessárias para que esse processo aconteça. Desse modo, as condições de apoio familiar e a perspectiva laboral da mulher são fatores sociais que incidem positivamente no exercício das funções parentais, visualizáveis a partir do sinais fenomênicos observados no roteiro IRDI.

Tais sinais fenomênicos também permitem observar o processo de organização do circuito pulsional que se estabelece sob os registros da oralidade, do olhar e da voz, tal como ressalta Catão ${ }^{25}$. A partir desses registros, corpo e linguagem vão sendo articulados, concebendo o sujeito no campo da linguagem e marcando sua passagem de puro Real a um corpo simbólico ${ }^{26}$. Assim, as operações que marcam a constituição psíquica tornam-se evidentes a partir dos seus efeitos indiretos observados no laço entre mãe e bebê. Por esse motivo, o roteiro IRDI se apoia neles para evidenciar se há algum impasse na constituição de um sujeito vir a ser.

\section{CONCLUSÃO}

A possibilidade de se verificar se os processos fundamentais à consituição psíquica estão ocorrendo, a partir de sinais fenomênicos observáveis na relação mãe-bebê, tem-se mostrado de fundamental importância na clínica de bebês. Cada vez mais, entende-se que a possibilidade de reconhecimento de impasses nessa constituição, podem promover mudanças significativas que contribuem para a saúde mental presente e futura do bebê.

$O$ roteiro IRDI permite verificar a qualidade da dinâmica do laço que a o bebê vem construindo com seus familiares no exercício das funções parentais e no 
processo de filiação, permitindo deslizamentos rumo à resolução de pequenos entraves ao desenvolvimento infantil, já a partir da escuta do profissional em puericultura que supõe um saber no familiar, ou mesmo os tempos do estabelecimento da demanda para um encaminhamento clínico. Na clínica, o processo de transferência será fundamental para que se possa compreender o bebê e seus pais de modo a produzir a ressiginificação e deslizamento de aspectos que obstaculizam o desenvolvimento. Por isso, a associação encontrada entre o roteiro IRDI e as variáveis sociodemográficas, obstétricas e psicossociais observadas nesta pesquisa não podem ser tomadas em relação de causa e efeito mas como fatores que aumentam a suscetibilidade de um bebê e sua família encontrarem os referidos obstáculos.

Pode-se pensar que algumas dessas variáveis, por se repetirem com certa frequência nos casos de risco psíquico e ao desenvolvimento, apontam para certas condições importantes que precisam ser consideradas no contexto das formações constitutivas do bebê. Nesse sentido, verificou-se que dentre as variáveis consideradas, os seguintes fatores mostraram, estatisticamente, ter relação com o desfecho risco psíquico: idade materna, a presença de uma atividade profissional da mãe, o sexo do bebê, o tipo de aleitamento até o sexto mês, a mãe possuir um cônjuge que the auxiliasse nos cuidados do bebê e como e onde a criança dormia.

Tais resultados reforçaram a ideia de que o risco psíquico e ao desenvolvimento é multifatorial, sem que se possa realizar uma leitura de causa e efeito sobre os fatos. Eles evidenciaram tendências que demonstram que fatores ambientais devem ser considerados na análise de risco ao desenvolvimento infantil, para além da prematuridade, habitualmente considerada no cuidado em puericultura.

A partir do estudo foi possível identificar fatores de risco à constituição psíquica e refletir sobre a inserção de assessoria e formação continuada em temas da constituição psíquica para profissionais da puericultura, pois não basta inserir protocolos ou roteiros de avaliação do desenvolvimento infantil na assistência, é preciso poder fazer intervenções que possam minimizar o risco de emergência de psicopatologias graves no desenvolvimento infantil e construir uma rede de referência para esses casos no sistema de saúde.

\section{REFERÊNCIAS}

1. Catão I. A linguagem como mistério revelado: voz e identificação nos autismos. In: Jerusalinsky A. (Org.). Dossiê autismo. São Paulo: Instituto Langage; 2015. p. 64-75.

2. Cullere-Crespin G, Parlato-Oliveira E. Projeto PREAUT. In: Jerusalinsky A. (Org.). Dossiê autismo. São Paulo, SP: Instituto Langage; 2015. p. 436-455.

3. Kupfer MC et. al. Valor preditivo de indicadores clínicos de risco para o desenvolvimento infantil: um estudo a partir da teoria psicanalítica. Lat. Am. Journal of Fund. Psychopath. 2009; 6(1): 48-68. Disponível em: http://abppparananorte.com.br/wp-content/ uploads/2017/11/IRDI.pdf

4. Kupfer MC et al. A pesquisa IRDI: resultados finais. In: Lenner R, Kupfer MC (Org.). Psicanálise com crianças: clínica e pesquisa. São Paulo: Editora Escuta, 2008. p. 221-230.

5. Laznik MC. Diversos olhares sobre o autismo. In: Jerusalinsky A. (Org.). Dossiê autismo. São Paulo: Instituto Langage. 2015 ; p. 56-61.

6. Saint-Georges $\mathrm{C}$ et. al. Sinais precoces do autismo: de onde vêm? Para onde vão? In: Busnel M-C, Melgaço R. (Orgs.). O bebê e as palavras: uma visão transdisciplinar sobre o bebê. São Paulo: Instituto Langage; 2013a. p. 49-58.

7. Saint-Georges C et. al. Do parents recognize autistic deviant behavior long before diagnosis? Taking into account interaction using computational methods. PLOS ONE. Jul. 2013; 6(7): 1-13. Disponível em: https://www.ncbi.nlm.nih.gov/pubmed/21818320. doi: 10.1371/journal.pone.0022393.

8. Sibemberg N. Atenção com o diagnóstico: a suspeita de autismo nem sempre se confirma. In: Jerusalinsky A. (Org.). Dossiê autismo. São Paulo: Instituto Langage; 2015. p. 97-105.

9. Winicott DW. Textos selecionados: da pediatria à Psicanálise. Rio de Janeiro: Francisco Alves; 1978.

10. Cavalcanti A. Apresentação e debate em torno da Pesquisa Multicêntrica de Indicadores Clínicos de Risco para o Desenvolvimento Infantil. In: Lenner R, Kup- 
fer MC. Psicanálise com crianças: clínica e pesquisa. São Paulo: Escuta; 2008. p. 51-54.

11. Crestani A, Mattana F, Moraes A, Souza APR. Fatores socioeconômicos, obstétricos, demográficos e psicossociais como risco ao desenvolvimento infantil. Rev. CEFAC. Jul./Ago. 2013; 15(4): 847-56. Disponível em: http://pepsic.bvsalud.org/scielo.php?scrip$\mathrm{t}=$ sci_arttext\&pid=S0104-12822017000200005. doi: $10.7322 /$ jhgd.114483.

12. Formiga C, Linhares MB. Avaliação do desenvolvimento inicial de crianças nascidas pré-termo. Rev. Esc. Enferm. 2009; 43(2): 472-80. Disponível em: http://www.scielo.br/pdf/reeusp/v43n2/a30v43n2.

13. Crestani A. Produção inicial de fala, risco ao desenvolvimento infantil e variáveis socioeconômicas, demográficas, psicossociais e obstétricas [dissertação]. Mestrado em Distúrbios da Comunicação Humana: Universidade Federal de Santa Maria: UFSM; 2012.

14. Jerusalinsky A. Tornar-se sujeito é possível ou impossível para um autista? Quando e quem decide isto? In: Jerusalinsky A. (Org.). Dossiê autismo. São Paulo: Instituto Langage; 2015. p. 22-51.

15. Kupfer MC et al. Metodologia IRDI nas creches: um acompanhamento do desenvolvimento psíquico na primeira infância. In: Kupfer MC, Szejer M. (Org.). Luzes sobre a clínica e o desenvolvimento de bebês: novas pesquisas, saberes e intervenções. São Paulo: Instituto Langage; 2016. p. 35-46.

16. Schjolberg $S$ et al. Predicting language development at age 18 months: data from the Norwegian Mother and Child Cohort Study. J Dev Behav pediatr. 2011; 32(5): 375-83. Disponível em: https://www. ncbi.nlm.nih.gov/pubmed/21546853. doi: 10.1097/ DBP.0b013e31821bd1dd.

17. Reuner G, Fields AC, Wittke A, Löpprich M, Pietz J. Comparison of developmental Bayley-III and Bayley-II in 7 month infants born preterm. Eur. J. Pediatr. Mar. 2013; 172(3): 393-400. Disponível em: https:// www.ncbi.nlm.nih.gov/pubmed/23224346. doi: 10.1007/s00431-012-1902-6.

18. Stephens B, Vohr B. Neurodevelopmental outcome of the premature infant. Pediatr Clin North Am. 2012; 56(3): 631-46. Disponível em: http:// www.scielo.br/scielo.php?script $=$ sci_arttext\&pi$\mathrm{d}=$ S1519-38292015000100047. doi: 10.1590/S151938292015000100004

19. Vanier C. Os mecanismos operantes no desenvolvimento psíquico do bebê prematuro e os riscos eventuais de patologia. In: Brusnel M-C, Melgaço R. (Org.). O bebê e as palavras: uma visão transdisciplinar sobre o bebê. São Paulo: Instituto Langage; 2013; p. 49-58.

20. Wanderley DB, Weise EBP, Brant JAC. O que há de avaliável No desenvolvimento infantil? Exame e discussão das escalas de avaliação do desenvolvimento infantil mais usadas no Brasil. In: Lerner R, Kupfer MCM. Psicanálise com crianças: clínica e pesquisa. Fapesp/Escuta: São Paulo; 2008.

21. Carlesso J, Souza A, Moraes A. Análise da Relação entre sofrimento psíquico materno e índices clínicos de risco para o desenvolvimento infantil. Rev CEFAC. 2014; 16(2): 500-9. Disponível em: http://www.redalyc.org/pdf/1693/169331137017.pdf.

22. Marin A, Piccinini C. Comportamentos e práticas educativas maternas em famílias de mães solteiras. Psicol. Est. Jan./Abr. 2007; 12(1): 1322. Disponível em: http://www.scielo.br/scielo. php?pid $=$ S1413 $=73722007000100003-\&$ scriptsci_abstract\&tlng $=$ pt. $\quad$ doi: $\quad 10.1590 / \$ 1413$ 73722007000100003 .

23. Cardoso L. Aleitamento materno: uma prática de educação para a saúde no âmbito da enfermagem obstétrica. [dissertação]. Mestrado em Educação: Universidade do Minho; 2007.

24. Beltrami L, Moraes A, Souza APR. Ansiedade materna puerperal e risco para o desenvolvimento infantil. Distúrb. Comum. Ago. 2013; 25(2): 229-39.

25. Catão I. O bebê nasce pela boca: voz, sujeito e clínica do autismo. São Paulo: Instituto Langage; 2009. Disponível em: https://revistas.pucsp.br/index.php/dic/ article/viewFile/16476/12373.

26. Elia L. O conceito de sujeito. Rio de Janeiro: Ed. Zahar; 2004. 
Recebido em: 15/06/2018

Aceito em: 08/08/2018 